УДК 37

\title{
ПОНЯТИЙНО-ГРАФИЧЕСКИЕ СРЕДСТВА НАГЛЯДНОСТИ: ВИЗУАЛЬНЫЕ ДИДАКТИЧЕСКИЕ РЕГУЛЯТИВЫ
}

\author{
Штейнберг Валерий Эмануилович \\ д.П.Н., профессор \\ Манько Наталия Николаевна \\ К.П.Н. \\ Вахидова Люция Вансеттовна \\ к.П.Н., доцент \\ БГПУ им. М. Акмуллы, г. Уфа
}

\begin{abstract}
Аннотация: Рассматривается проблема развития дидактических регулятивов на основе понятийно-графических средств наглядности. Актуальность проблемы возрастает в связи с повсеместным дистанционным обучением и с расширением самообразования. Представлено направление визуальные дидактические регулятивы логико-смыслового типа.

Ключевые слова: Визуализация, понятийно-графические средства наглядности, логико-смысловое моделирование, визуальные дидактические регулятивы.
\end{abstract}

\section{CONCEPT-GRAPHIC VISUAL AID: VISUAL DIDACTIC REGULATIONS}

\section{Steinberg V. E. \\ Manko N.N. \\ Vakhidova L. V.}

\begin{abstract}
The problem of the development of didactic regulations on the basis of conceptual-graphic means of visualization is considered. The urgency of the problem is increasing in connection with the widespread distance learning and with the expansion of self-education. The direction is presented - visual didactic regulators of the logical-semantic type.
\end{abstract}

Key words: Visualization, conceptual-graphic means of visualization, logicalsemantic modeling, visual didactic regulations. 
В образовании группа понятийно-графических средств наглядности представляют собой важные инструменты поддержки, направления и регуляции учебной познавательной деятельности. В профессиональной деятельности также широко используются понятийно-графические концепт-карты, фреймы и структурно-логические схемы. Значимость данных средств в настоящее время значительно возрастает при повышении требований к самоорганизации, к самоконтролю обучающихся. В то же время дидактические регулятивы как инструменты учебной деятельности исследованы недостаточно, в отличие от отраслей, где регулятивы исследованы и используются [1].

В структуре средств знаково-символической наглядности (числовые отношения, схемы, графики, чертежи и т. д.), понятийно-графические средства наглядности занимают важное место, так как включают современные популярные средства: семантические сети, фреймы, концепт-карты, структурно-логические схемы, а также логико-смысловые модели (рис. 1). Понятийно-графические средства наглядности, как и знаково-символические в целом, способствуют реализации принципа наглядности - соединению наглядности преподавания с абстрактным мышлением обучающегося [2, 117]. В образовании, как отмечено выше, регулятивы должны быть предметом детального научного исследования, однако обнаружить соответствующую тематику по тэгам «дидактические регулятивы» в планах научных работ РАО, в публикациях Электронной научной библиотеки и в Интернете не удается. В создавшихся условиях адекватно отвечать повышенным требованиям к самоорганизации и саморегуляции деятельности обучающегося, по мнению авторов, затруднительно. 


\section{ЗНАКОВО-СИМВОЛИЧЕСКИЕ СРЕДСТВА НАГЛЯДНОСТИ}

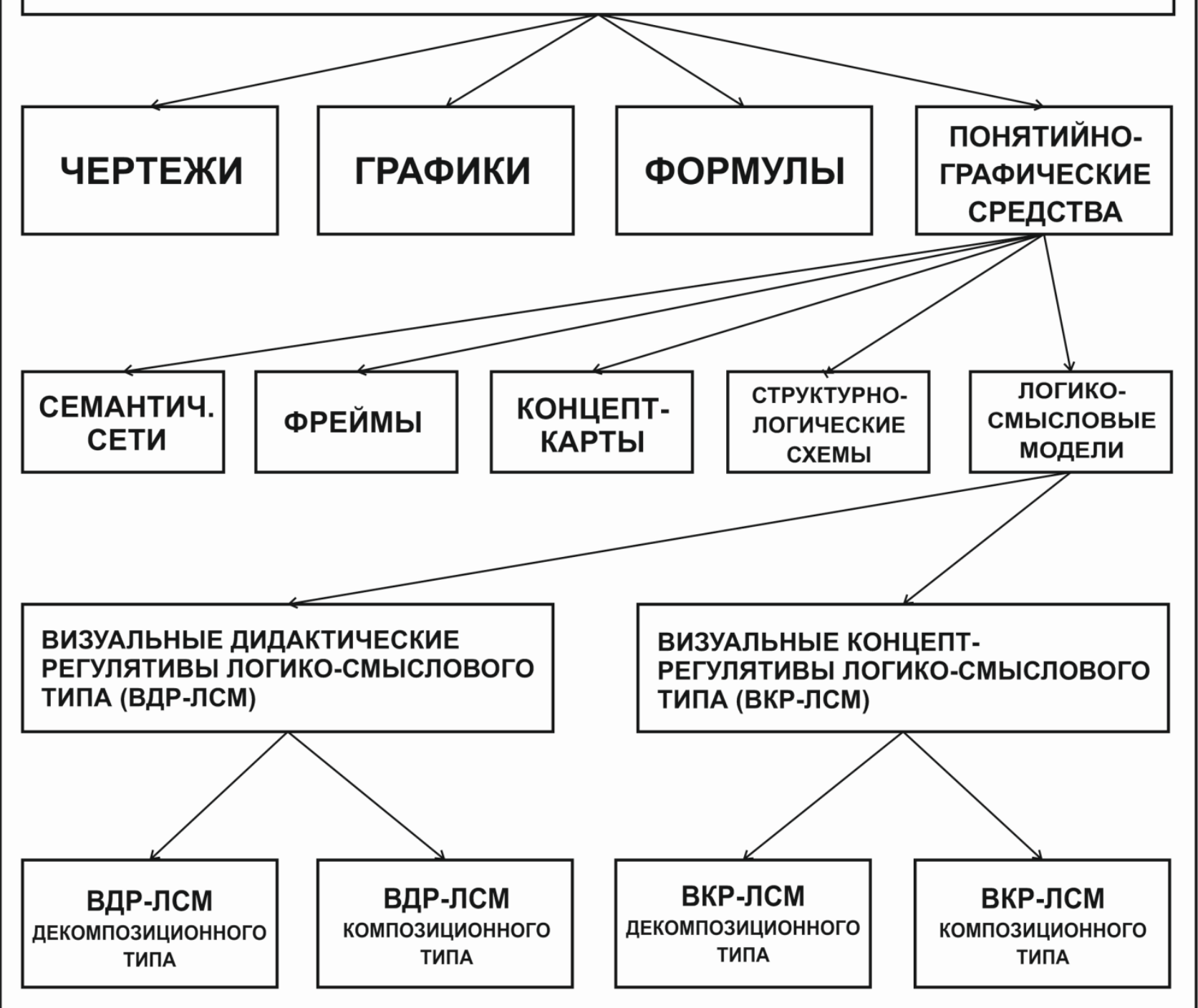

Рис. 1. Понятийно-графические средства наглядности

Основой дидактических свойств понятийно-графических средств наглядности служат принципы когнитивной визуализации знаний (структурирование содержания, связывание элементов содержания и свертывание обозначений элементов содержания и связей между ними), обусловливающие условный изоморфизм известных (рис. 2). 


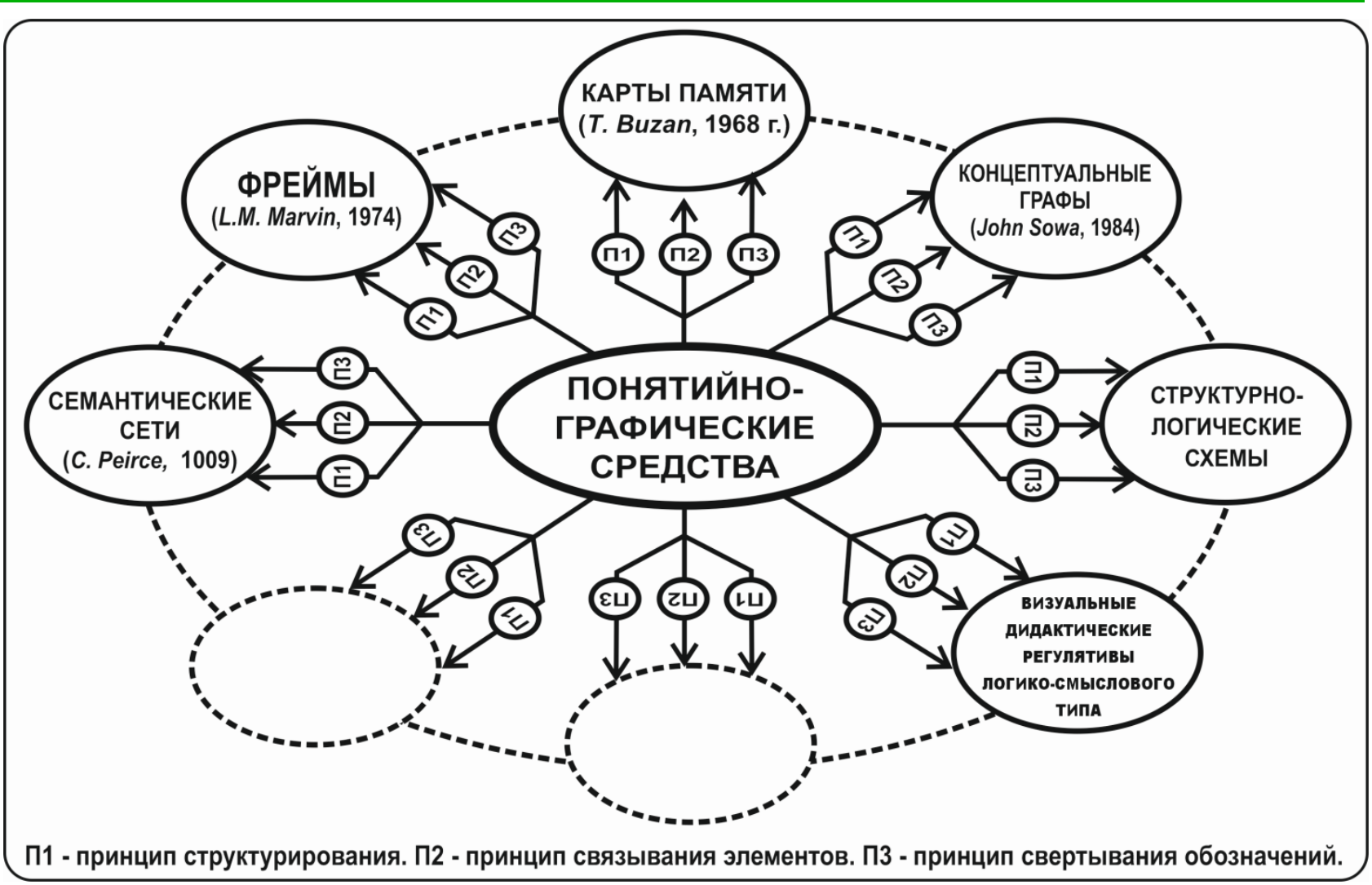

Рис. 2. Изоморфизм логико-смыслового представления знаний

Хронологически данные принципы задействуются поначалу не полностью, но с началом использования метода логико-смыслового моделирования знаний, представленных на естественном языке, используются во все большей степени. Эти же принципы реализуются в методе логикосмыслового моделирования, разработанного отечественными учеными [3] и адаптированного для построения логико-смысловых моделей [4].

Основой визуальных дидактических регулятивов логико-смыслового типа являются логико-смысловые модели координатно-матричного типа [4], которые представляют собой объект семиотики (рис.3). Логико-смысловые модели как синтез образного графического основания и свернутого содержания, представленного в виде узловых элементов (УЭС), обладают комплексом важных свойств: модельными, иллюстративными, опорными и регулятивными. Они применяются для поддержки основных (инвариантных) форм учебной познавательной деятельности: предметно-ознакомительной, аналитико-речевой и моделирующе-фиксирующей [5]. 


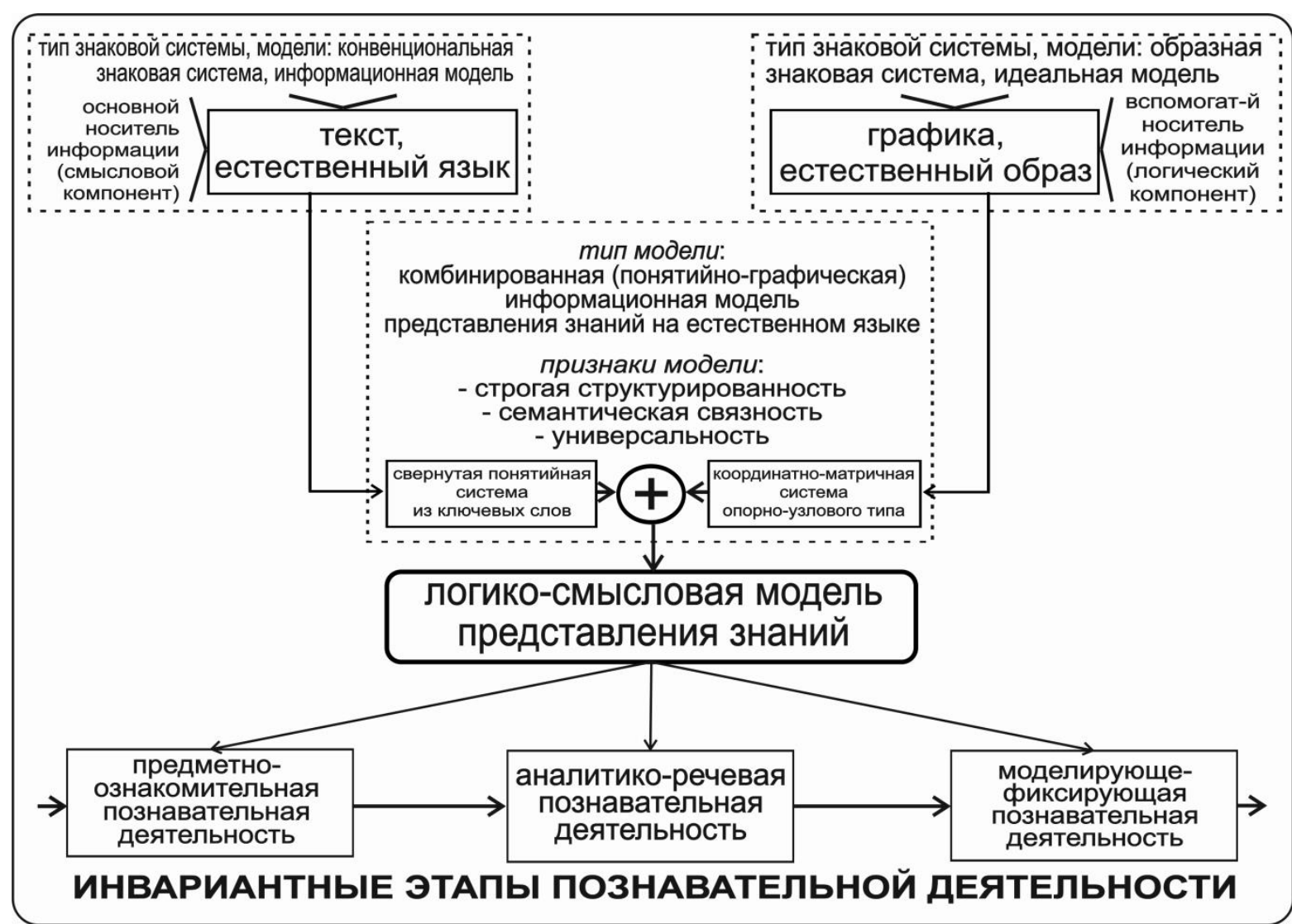

Рис. 3. Логико-смысловые модели - объект семиотики

В педагогическом образовании, в контексте задачи создания визуальных дидактических средств с регулятивными свойствами, необходимо выполнить следующие важные требования: создавать не интуитивным рисованием, а методом логико-смыслового моделирования содержания учебного материала или учебной деятельности с осмысленным применением универсальных учебных действий; визуальную реализацию осуществлять с помощью природосообразной, удобно воспринимаемой зрительно, универсальной графики. В этом плане недооцененной является универсальная продуктивная метафора «координаты существования» объекта, процесса, явления и т. д.

Пример регулятива «Визуальная самоэффективность педагога» приведен на рис. 4 (где ВДР-ЛСМ - визуальный регулятив логико-смыслового типа; ВКР-ЛСМ - визуальный концепт-регулятив логико-смыслового типа). 


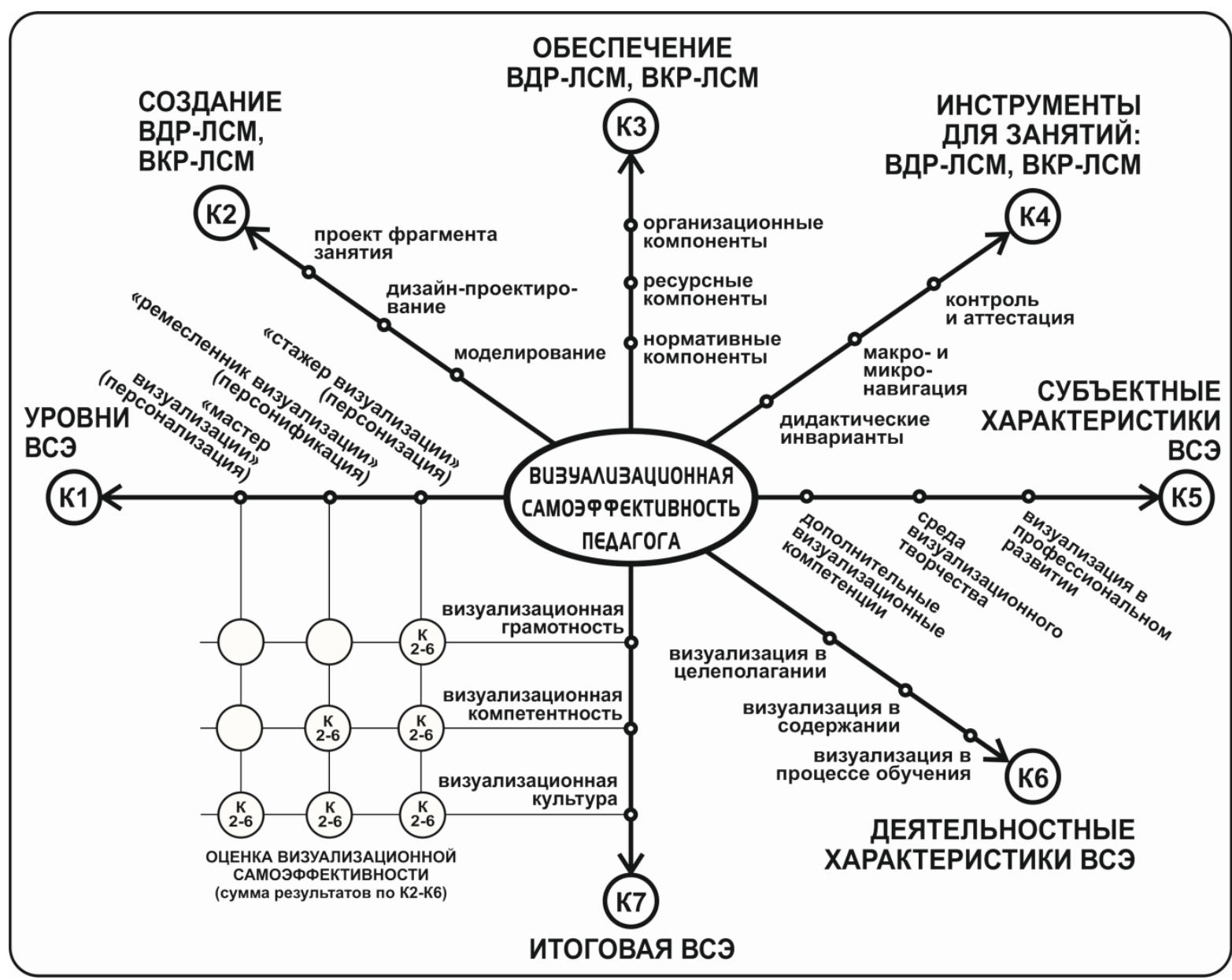

\section{Рис. 4. Регулятив «Визуальная самоэффективность педагога»}

У проектируемых по данной технологии визуальных дидактических регулятивов логико-смыслового типа информационно-опорные свойства обеспечиваются благодаря структурированной информации, представленной в хорошо воспринимаемой координатно-матричной графике, а информационнорегулятивные свойства - благодаря визуально представленной логике преобразования информации или выполнения учебной деятельности.

Для освоения технологии формирования самоэффективности специалиста потребовались и были разработаны подход к формированию самоэффективности специалиста [7], а также Электронная программа «Профессиональная самоэффективность педагога» [8], в интерактивном интерфейсе которой использован концепт-регулятив композиционного типа (рис. 8).

Визуальные концепт-регулятивы логико-смыслового типа также были использованы при разработке ряда прикладных проектов и компьютерных программ к ним: «Обучающего программного комплекса “Жизнь 
замечательных мелодий”» [9] и «Обучающей программы «Лонгэтюдный проект “Дидактическая микроюмористика”» [10].

Общий вывод. Визуальные дидактические регулятивы являются актуальным направлением развития дидактических средств наглядности на основе понятийных и графических элементов. Разработанные визуальные дидактические регулятивы логико-смыслового типа дополняют известные понятийно-графические средства наглядности и расширяют арсенал инструментов педагога и обучающегося. Понятийно-графические конструкции регулятивов являются объектами авторского права и интеллектуальной собственности. Опытно-экспериментальная апробация визуальных дидактических регулятивов логико-смыслового типа в условиях дистанционного обучения подтвердила полезность их применения при проведении занятий [11]. Важно отметить - визуальные дидактические регулятивы логико-смыслового типа - не алгоритмоподная наглядность, а «знаниевый конструктор», инициирующий учебную деятельность и творческие усилия педагога и обучающегося.

\section{Термины к статье.}

Понятийно-графические средства наглядности - зрительно воспринимаемые изображения структуры отображаемого объекта и связей между ее частями, обозначаемых с помощью ключевых слов и оформляемых с помощью графических элементов. К таким средствам относятся ментальные карты, фреймы, структурно-логические схемы и т.п.

Логико-смысловое моделирование знаний - способ моделирования знаний путем декомпозиции рассматриваемого объекта или процесса, описание которого представлено на естественном языке (языке обучения), с помощью пакета универсальных учебных действий и размещения результатов моделирования на опорно-узловой системе координат.

Визуальный дидактический регулятив логико-смыслового типа зрительно воспринимаемое изображение понятийно-графического средства наглядности, проектируемого методом визуализации логико-смыслового моделирования знаний с размещением результатов моделирования - узловых элементов содержания и их связей, обозначаемых с помощью ключевых слов, на опорно-узловой координатно-матричной системе.

Визуальный концепт-регулятив логико-смыслового типа - зрительно воспринимаемое изображение понятийно-графического средства наглядности, проектируемого методом визуализации логико-смыслового моделирования 
знаний с размещением результатов моделирования - узловых элементов содержания и их связей, обозначаемых с помощью ключевых слов, на опорноузловой координатно-матричной системе; в четвертом квадранте регулятива размещается матрица, связывающая проектируемые компетенции с результатом их формирования.

\section{Примечание}

При поддержке Внутривузовского гранта БГПУ им. М.Акмуллы «Теория и технология моделирования регулятивов логико-смыслового типа для образовательных проектов».

\section{Список литературы}

1. Штейнберг В.Э., Манько Н.Н. Современный дидактический регулятив: теория и технология // Отечественная и зарубежная педагогика. 2019. T. 1. № 5 (62). C.160-183. 160-183. doi 10.24411/2224-0772-2019-10038

2. Салмина Н.Г. Знак и символ в обучении. - М.: Изд-во МГУ, 1988. С. 117.

3. Субботин М. М. О логико-смысловом моделировании управленческих решений // Научное управление обществом. - М. Мысль, 1980, Вып. 13. С. 23-24.

4. Теоретико-методологические основы дидактических многомерных инструментов для технологий обучения (В. Э. Штейнберг) - Официальные документы УрО РАО//Образование и наука. 2001. № 4. С. 3-6.

5. Штейнберг В.Э., Манько Н.Н. Визуальные дидактические регулятивы логико-смыслового типа // Образование и наука. 2017. Том 19. № 9. С. 9-31.

6. Штейнберг В.Э., Вахидова Л.В., Габитова Э.М. Анализ профессионально-образовательной проблематики при обосновании компетенций специалиста производственного кластера. Образование и наука. 2019; 21(1): 59-81. https://doi.org/ 10.17853/1994-5639-2019-1-59-81

7. Вахидова Л.В., Манько Н.Н., Габитова Э.М., Штейнберг В.Э. Визуализация персонифицированной информационно-образовательной среды // Образовательные технологии. 2018. № 1. С. 34-47.

8. Электронная программа «Профессиональная самоэффективность педагога». Вахидова Л.В., Штейнберг В.Э., Ткаченко Е.В., Хакимжанов Р.С., Манько Н.Н., Габитова Э.М., Галиахметова Э. М., Горлицына О.А. Свидетельство RU 2018614157 от 02.04.2018. Режим доступа: 
https://www.fips.ru/iiss/document.xhtml?faces-redirect=true\&id=54a5f9f6fb394e24 e03da3de764c736c

9. Обучающий программный комплекс «Жизнь замечательных мелодий». Штейнберг В. Э., Габитова Э. М., Ткаченко Е. В., Манько Н. Н., Вахидова Л. В., Саитова Л. Р. Свидетельство RU 2018612220 от 14.02.2018. Режим доступа: https://new.fips.ru/registers-doc-view/fips_servlet?DB=EVM\&Doc Number $=2018612220 \&$ TypeFile $=$ html

10. «Обучающая программа «Лонгэтюдный проект "Дидактическая микроюмористика». Штейнберг В.Э. Свидетельство RU 2020618692 от 03.08.2020. Режим доступа: https://new.fips.ru/registers-doc-view/fips_servlet?DB= EVM\&DocNumber=2020618692 \&TypeFile $=\mathrm{html}$

11. Сайт Научно-иследовательской лаборатории моделирования визуальных регулятивов логико-смыслового типа. Режим доступа: https://bspu.ru/unit/286/news. 